\title{
Drinking water treatment using a groundwater source-assessment of three technological variants through pilot-scale investigations
}

 \\ \& F. Manea ${ }^{2}$ \\ ${ }^{1}$ SC Aquatim SA Timisoara, Romania \\ ${ }^{2}$ Faculty of Industrial Chemistry and Environmental Engineering, \\ Politehnica University of Timisoara, Romania
}

\begin{abstract}
Pilot studies offer an economical method to test alternative and innovative treatment technologies for the development of new or enhanced existing water treatment technologies, without affecting the existing process. In this study, three technological variants for the drinking water treatment at pilot-scale were investigated using a groundwater source. Arsenic, total organic carbon, dissolved organic carbon, turbidity, iron and manganese exceeded the maximum allowance concentration imposed by the regulation for the groundwater source used in this study. The technological variants consisted of several unitary processes, e.g., sandbased filtration, ultrafiltration and reverse osmosis for the first variant, aluminum salts-based coagulation, filtration, ultrafiltration and reverse osmosis for the second variant and the third variant contained $\mathrm{O}_{2}$-based oxidation, filtration, ultrafiltration and reverse osmosis. The water flow of $750 \mathrm{Lh}^{-1}$ was tested for all technological variants for time duration of four hours and the water samples were monitored after each unitary process. By sand-based filtration step preceded or not by oxidation and coagulation, allowed that the turbidity and iron parameters to meet the requirements imposed by legislation. Arsenic was eliminated by filtering on a special iron-based filtration unit. Under studied hydrodynamic conditions, the coagulation process occurred on the sand-based filter that led to the filter fouling after two functioning hours, and no whole technological flow was achieved. Ultrafiltration and especial, reverse osmosis allowed removing the organic load expressed by TOC (total organic carbon) and DOC (dissolved organic carbon). Taking into account the technical performance and the simplicity, the first
\end{abstract}


technological variant should be suitable for the drinking water treatment using the above-presented groundwater source. However, to avoid the membrane fouling for reverse osmosis and as consequence, the increased costs, the further optimization for the coagulation process is required to be coupled with the sandfiltration and integrated in the drinking water treatment technology.

Keywords: pilot-plant investigations, drinking water treatment, groundwater source, arsenic, organic load.

\section{Introduction}

Nowadays, the attention of the drinking water provider is to assure the drinking water quality in accordance with the more stringent requirements imposed by the legislation $[1,2]$. Groundwater represents a valuable source of drinking water [3, 4], especially for small communities. However, the drinking water quality indicators using groundwater source must be improved and sometimes, they do not meet the requirements imposed by the legislation. For example, in the west side of Romania, arsenic pollution of groundwater is reported $[5,6]$. In addition, there are groundwater sources characterized by high turbidity and the organic loading. Sometimes, iron and manganese are presented in the groundwater at the values exceeding the legal limits.

Conventional groundwater treatment for the chemical parameters includes the aeration and the sand-filtration, which are not enough to assure the adequate public health conditions and the integration of the advanced processes for the water treatment flow is required.

Pilot-plant studies offer an economical method to test alternative and innovative treatment technologies for the development of new or enhanced existing water treatment technologies, without affecting the existing process [712]. In fact, this pilot-plant stage should be considered compulsory for the treatability stage after the design of the drinking water treatment technology and before to build the drinking water treatment plant. Numerous researchers focused on the membrane-based processes usage and integration within the drinking water treatment technology $[8,12]$. The membrane fouling represents a major aspect that indicates the process performance [13-15].

It is obviously that for designing a feasible drinking water treatment pilot-plant, the results at the laboratory-scale are considered as reference points together with the literature documentation corroborated with the groundwater quality characteristics.

The present research work is focused on testing three technological variants for the drinking water treatment using groundwater source, consisted of several unitary processes, e.g., sand-based filtration, ultrafiltration and reverse osmosis for the first variant, aluminum salts-based coagulation, filtration, ultrafiltration and reverse osmosis for the second variant and the third variant contained $\mathrm{O}_{2}$-based oxidation, filtration, ultrafiltration and reverse osmosis. Selection of the simplest conventional technological flow incorporating ultrafiltration and reverse osmosis taken into account to guarantee the production of high quality drinking water in terms of the chemical composition. 
This research studied the potential of the nanofiltration and reverse osmosis process to improve water quality from the holistic point of view, avoiding membrane fouling and to complement or replace conventional treatment, especially to design and to build it for new small communities.

\section{Experimental}

The pilot-scale flexible module used in this study consisted of several unitary processes, i.e., sand-based filtration, aluminum salts-based coagulation, O2-based oxidation ultrafiltration and reverse osmosis, which are combined as three technological variants (see Figure 1). The first technological variant (TV1) consisted of sand-based filtration, ultrafiltration and reverse osmosis, the second technological variant (TV2) consisted of aluminum salts-based coagulation, filtration, ultrafiltration and reverse osmosis and the third variant (TV3) contained $\mathrm{O}_{2}$-based oxidation, filtration, ultrafiltration and reverse osmosis.



Figure 1: Schematic representation of the technological flow for the pilot-plant.

The degasification step was used to removal the gases from ground water in order to avoid the modification of the groundwater matrix.

For the coagulation step, Sachtoklar coagulation agent was used at the dose of $14 \mathrm{mgL}^{-1}$ aluminum that was previously determined at the laboratory-scale, using an in-liner mixer generating a "coagulation on filter" process.

Special filtration was designed especially for arsenic removal. The filtering material consisted of commercial iron oxyhydroxides provided by Gruppo ZILIO, Italy. The composition of the filtering material is $\mathrm{FeO}(\mathrm{OH})$ and $\mathrm{Fe}(\mathrm{OH})_{3}$ with the dimensions ranged between 0.2 and $2 \mathrm{~mm}$.

The ultrafiltration unit was provided by ProMinent Romania, and it was operated using a membrane of 4", a working pressure of 1.5-5 bar and a transmembrane pressure (TMP) of 2.5 bar. The washing volume is maximum $2 \%$ of filtered volume.

The reverse osmosis unit provided also, by ProMinent Romania, is equipped with two membranes of minimum 2.5", a working pressure of 3-6 bar with an efficiency for salts removal of $90-95 \%$. 
The raw water was storage in a container and the pilot plant was operated four hours per days. Periodically, samples were taken from feed and after each unitary process and analysed for the determination of turbidity, chemical oxygen demand (COD), total organic carbon (TOC), iron, manganese, arsenic. Standardized methods were used for analyzing the water quality parameters, i.e., SR EN ISO 7027:2001 for turbidity, SR EN ISO 8467:2001 for COD, SR EN 1484:2001 for TOC and DOC, and internal AAS method for iron, manganese and arsenic.

Table 1: Groundwater source quality parameters that exceeded the legal limit.

\begin{tabular}{|l|c|c|c|}
\hline \multicolumn{1}{|c|}{ Parameter } & MU & $\begin{array}{c}\text { Legal limit* } \\
\text { admisă }\end{array}$ & Value \\
\hline \hline Turbidity & $\mathrm{NTU}$ & 5.00 & 8.4 \\
\hline Dissolved organic carbon & $\mathrm{mg} / \mathrm{L}$ & 3.00 & 5.32 \\
\hline Total organic carbon & $\mathrm{mg} / \mathrm{l}$ & 3.00 & 5.42 \\
\hline Iron & $\mathrm{mg} / \mathrm{l}$ & 0.10 & 1.00 \\
\hline Manganese & $\mathrm{mg} / \mathrm{l}$ & 0.05 & 0.19 \\
\hline Arsenic & $\mu \mathrm{g} / \mathrm{l}$ & 10.00 & 130.00 \\
\hline
\end{tabular}

*In accordance with the Romanian legislation (Law no.311/2004 for modifying and completing Law no. 458/2002 for drinking water quality).

\section{Results and discussion}

Based on the groundwater characteristics, the technological variants proposed in this study take into account on the hand, the simplest technological flow for the drinking water treatment and on the other hand, the effect of nanofiltration and reverse osmosis process on the water quality in direct relation to the parameters that exceeded the legal limits. The comparative results for each parameter are presented in Figures 2-7.

The turbidity represents the parameter that informed about the presence of suspension in water. It is obviously that after sand-filtering the turbidity is removed for all TVs, and the coagulation process using aluminium coagulation agent improved the turbidity removal. It should be noticed that the $\mathrm{O}_{2}$-oxidation process did not influence the turbidity removal, probably the turbidity is given by mineral suspensions and not organic. It must be mentioned that TV3 was applied after three days of the storage of the raw water, and a settling process occurred in the container, evidenced by turbidity degreasing in raw water. Also, the nanofiltration and reverse osmosis units led to greater reducing turbidity.

Chemical oxygen demand (COD) parameter that is responsible mainly by the organic load oxidizable by $\mathrm{KMnO}_{4}$ oxidation agent did not exceeded the legal limit but it is near to legal limit and its evolution was followed. Only coagulation and reverse osmosis processes allowed COD parameter decreasing, which should be due to the dissolved or colloidal form of the organic load. For TV2, where the coagulation process occurred as "coagulation on filter" after two hours of 


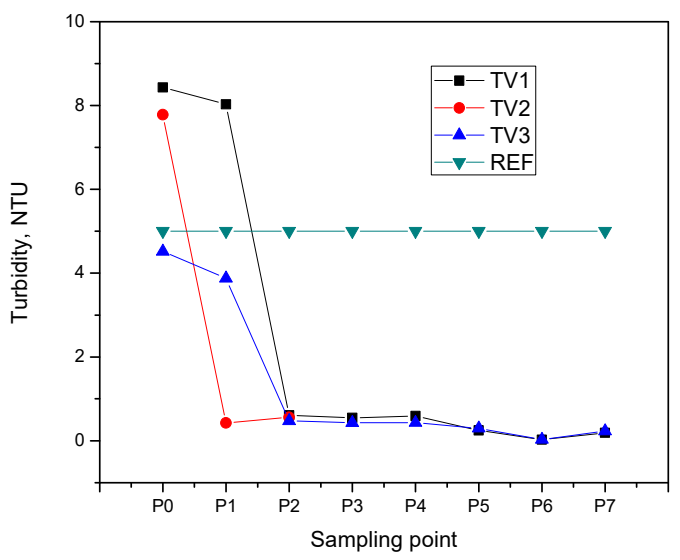

Figure 2: The comparative assessment of the turbidity evolution during the technological flow for each technological variant tested in comparison with the legal limit (REF).

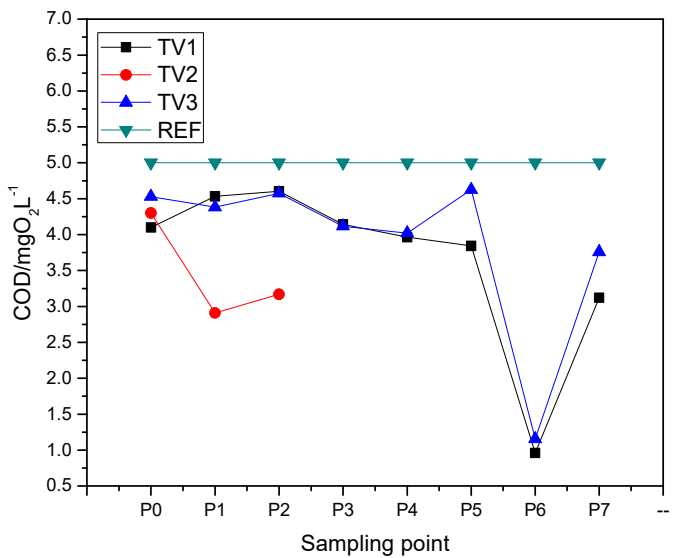

Figure 3: The comparative assessment of COD evolution during the technological flow for each technological variant tested in comparison with the legal limit (REF).

operation, the sand based filter was broken because of overloaded on the filter due to the "sludge" formed by the coagulation process.

Other parameters that inform about organic loading are TOC and DOC parameters. Their values are similar that means that organic load is as dissolved form, and only the evolution of TOC is presented in Figure 4. This aspect is confirmed also by the TOC evolution during the technological flow. Neither sandfiltering nor $\mathrm{O}_{2}$-based oxidation process allows TOC removal, which confirms that main TOC component is as dissolved form. A better removal of TOC was achieved by the coagulation process, but not enough to meet the legal limit. Only reverse osmosis led to very effective removal of TOC to meet the legal requirement, which 




Figure 4: The comparative assessment of TOC evolution during the technological flow for each technological variant tested in comparison with the legal limit (REF).

reclaims the reverse osmosis integration within drinking water treatment using this type of the groundwater source.

One of the stringent problems in the area of groundwater source is arsenic presence. Arsenic concentration in groundwater is ten times higher than the legal limit, and its removal is required. It is well-known that iron-based oxides exhibit the great sorption capacity for arsenic $[16,17]$, and special iron oxyhydroxides provided by Gruppo ZILIO was used to equip the second stage of filtering. This special filtering stage assures the effective removal of arsenic to reach the arsenic value below the legal limit. The coagulation process using aluminum allowed low arsenic removal efficiency but the future tests will envisage using iron coagulation agents. For these low concentration values of arsenic (about $2 \mu \mathrm{gL}^{-1}$ ), no effect of reverse osmosis was noticed.

Other parameters that exceeded the legal limit are iron and manganese. Their evolution during pilot plant operation is presented in Figures 5 and 6. It can be seen that only by simple settling an important part of iron is removed (see P0 for TV3, Figure 6), which means that dissolved and suspended iron forms are presented in this type of groundwater. Also, by simple sand-filtering a part of iron is removed. In fact, the degassing stage assures an aeration by which iron is oxidized as hydroxides and easily removed by filtering. Coagulation stage occurred with the mixture of aluminum and iron-based hydroxides and it stimulates the removal of both turbidity and iron.

Manganese dissolved in groundwater can be removed effectively by the reverse osmosis process. Ultrafiltration step allowed reducing manganese but not to reach the legal limit. At the final step, by mixing $75 \%$ effluent of ultrafiltration step with $25 \%$ effluent from reverse osmosis recommended in the literature [18], the legal limit for manganese is exceeded and the reverse osmosis step is compulsory. 


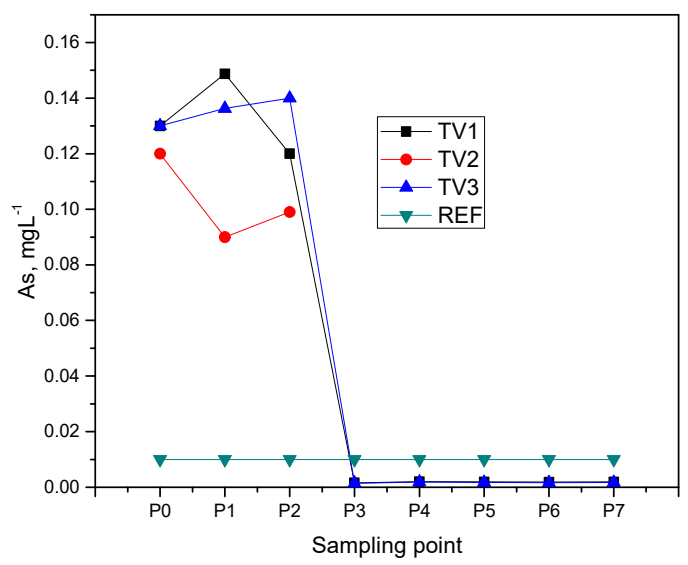

Figure 5: The comparative assessment of arsenic evolution during the technological flow for each technological variant tested in comparison with the legal limit (REF).

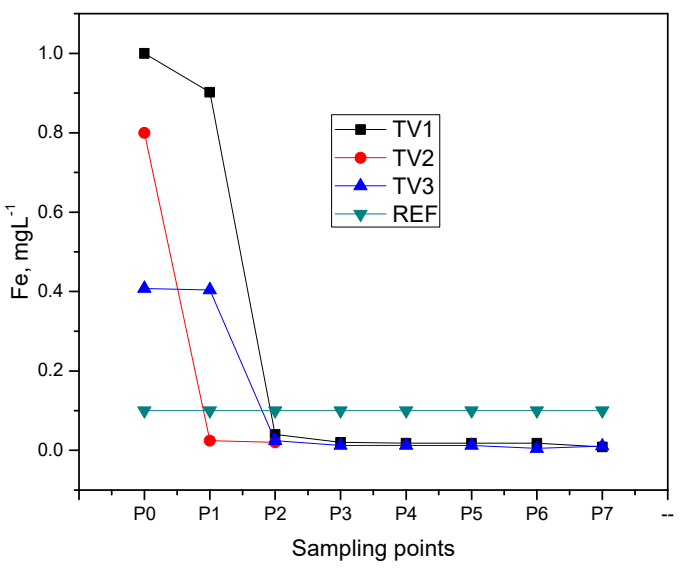

Figure 6: The comparative assessment of iron evolution during the technological flow for each technological variant tested in comparison with the legal limit (REF).

The overall performances of the technological variants proposed in this study were assessed in terms of removal degree (RD) related to final effluent and raw groundwater (presented in Table 2). 


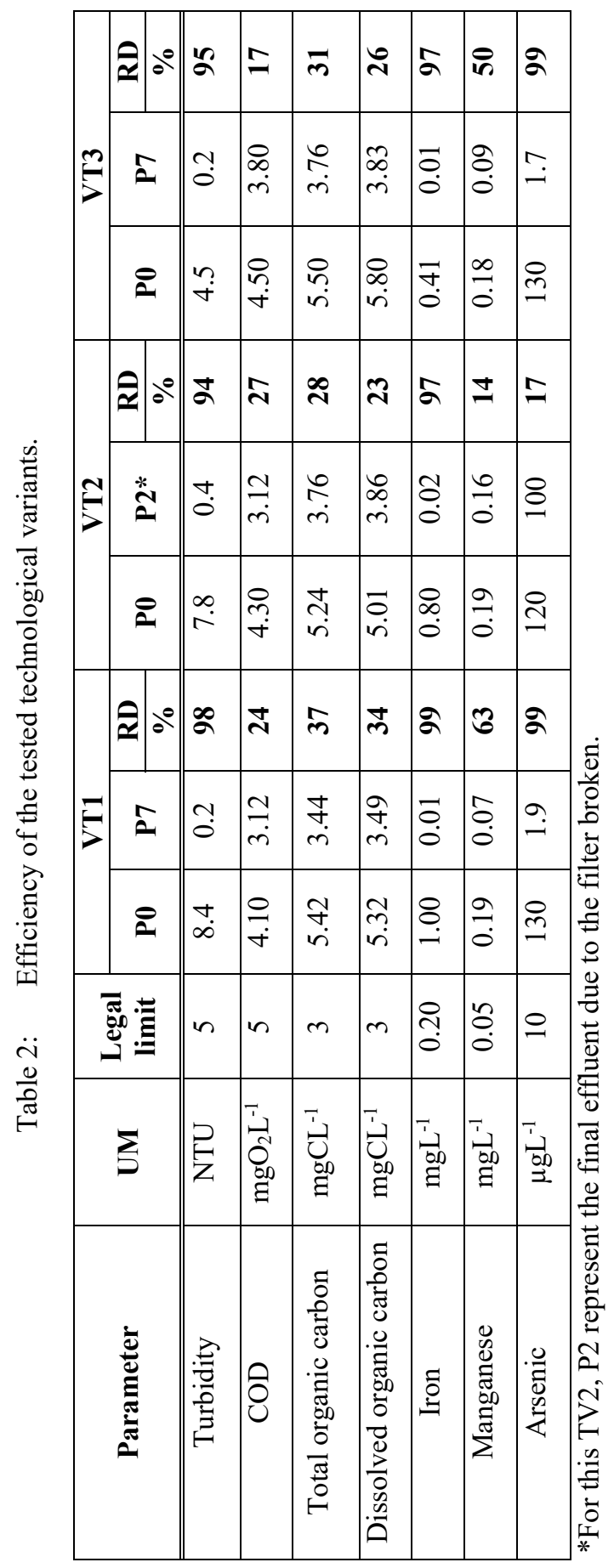




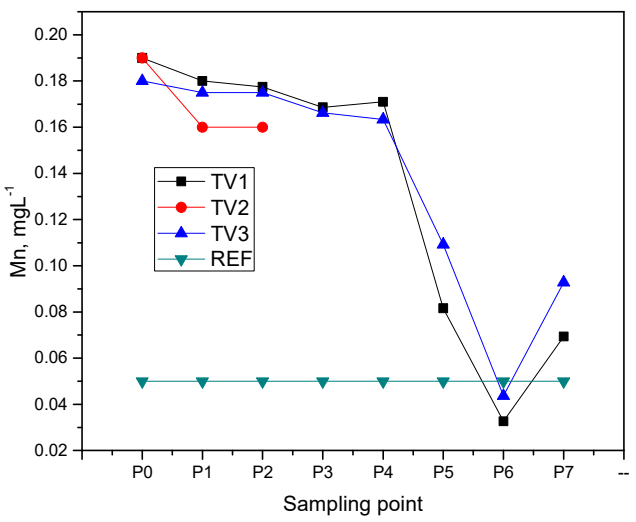

Figure 7: The comparative assessment of $\mathrm{Mn}$ evolution during the technological flow for each technological variant tested in comparison with the legal limit (REF).

Based on the results of the overall assessment, TV1 is the most suitable from the technical and economical point of view, with the mention of $100 \%$ exploitation of the reverse osmosis process.

\section{Conclusions}

In this study, for the drinking water treatment at pilot-scale, three technological variants consisted of several unitary processes selected in relation to the groundwater characteristics and the literature, i.e., sand-based filtration, ultrafiltration and reverse osmosis for the first variant (TV1), aluminum saltsbased coagulation, filtration, ultrafiltration and reverse osmosis for the second variant (TV2) and the third variant contained $\mathrm{O}_{2}$-based oxidation, filtration, ultrafiltration and reverse osmosis (TV3) were investigated using a groundwater source.

The groundwater quality parameters of turbidity, total organic carbon, dissolved organic carbon, arsenic, iron and manganese exceeded the legal limits imposed by the Romanian regulations.

Sand-based filtration step preceded or not by oxidation and coagulation, allowed that the turbidity and iron parameters to meet the requirements imposed by legislation. Arsenic was eliminated by filtering on a special iron oxyhydroxydes-based filtration unit. Under studied hydrodynamic conditions, the coagulation process occurred on the sand-based filter that led to the filter fouling after two functioning hours, and no whole technological flow was achieved. Manganese dissolved in groundwater can be removed effectively by the reverse osmosis process. Also, reverse osmosis allowed removing the organic load expressed by TOC (total organic carbon) that is majority as DOC (dissolved organic carbon). An important part of iron is removed by simple sand-filtering enhanced by degassing stage. 
Taking into account the technical performance, the first technological variant including the reverse osmosis should be suitable for the drinking water treatment using the above-presented groundwater source. To avoid the membrane fouling for ultrafiltration and especial, for reverse osmosis, their integration within a conventional technological flow for the drinking water treatment is effective.

\section{Acknowledgement}

This work was supported partially by a grant of the Romanian National Authority for Scientific Research, CNCS - UEFISCDI, project number PN-II-ID-165/2011, partially by PNII-PCCA-60/2012.

\section{References}

[1] Drinking Water Directive 98/83/EC.

[2] Romanian Law no. 311/2004 regarding drinking water quality.

[3] de Vet, W.W.J.M., Dinkla, I.J.T., Muyzer, G., Rietveld, L.C. \& van Loosdrecht, M.C.M., Molecular characterization of microbial populations in groundwater sources and sand filters for drinking water production. Water Research, 43, pp.182-194, 2009.

[4] Ayotte, J.D., Belaval, M., Olson, S.A., Burow, K.R., Flanagan, S.M., Hinkle, S.R. \& Lindsey, B.D., Factors affecting temporal variability of arsenic in groundwater used for drinking water supply in the United States. Science of the Total Environment. 505, pp. 1370-1379, 2015.

[5] Pop, A., Baciu, A., Wanko, G., Bodor, K., Vlaicu, I. \& Manea, F., Assessment of electrocoagulation process application in arsenic removal from drinking water. Environmental Engineering and Management Journal, in press.

[6] Butts C.D., Bloom M.S., Neamtiu I.A., Surdu S., Pop C., Atanasiu D., Fitzgerald E.F. \& Gurzau E.S., A pilot study of low-moderate drinking water arsenic contamination and chronic diseases among reproductive age women in Timis County, Romania. Environmental Toxicology and Pharmacology, 40, pp. 1001-1004, 2015.

[7] Hilal, N., Kochkodan, V., Al Abdulgader, H., Mandale, S. \& Al-Jlil, S.A., A combined ion exchange-nanofiltration process for water desalination: I. sulphate-chloride ion-exchange in saline solutions. Desalination, 363, pp. 44-50, 2015.

[8] Peiris, R.H., Jaklewicz, M., Budman, H., Legge, R.L. \& Moresoli, C., Assessing the role of feed water constituents in irreversible membrane fouling of pilot-scale ultrafiltration drinking water treatment systems. Water Research, 47(10), pp. 3364-3374, 2013.

[9] García-Vaquero, N., Lee, E., Castañeda, R.J., Cho, J. \& López-Ramírez, J.A., Comparison of drinking water pollutant removal using a nanofiltration pilot plant powered by renewable energy and a conventional treatment facility. Desalination, 347, pp. 94-102, 2014. 
[10] Plakas, K.V., Sklari, S.D., Yiankakis, D.A., Sideropoulos, G.T., Zaspalis, V.T. \& Karabelas, A.J., Removal of organic micropollutants from drinking water by a novel electro-Fenton filter: Pilot-scale studies. Water Research, 91, pp. 183-194, 2016.

[11] Latva, M., Inkinen, J., Rämö, J., Kaunisto, T., Mäkinen, R., Ahonen, M., Matilainen, J. \& Pehkonen, S., Studies on the magnetic water treatment in new pilot scale drinking water system and in old existing real-life water system, Journal of Water Process Engineering, 9, pp. 215-224, 2016.

[12] Lopes, M.P., Matos C.T., Pereira, V.J., Benoliel, M.J., Valério M.E., Bucha L.B., Rodrigues, A., Penetra, A.I., Ferreira, E., Cardoso, V.V., Reis, M.A.M. \& Crespo, J.G., Production of drinking water using a multi-barrier approach integrating nanofiltration: A pilot scale study. Separation and Purification Technology, 119, pp. 112-122, 2013.

[13] Her, N., Amy, G., Plottu-Pecheux, A. \& Yoon, Y., Identification of nanofiltration membrane foulants. Water Research, 41(17), pp. 3936-3947, 2007.

[14] Guo, W., Ngo, H.H. \& Li, J., A mini-review on membrane fouling. Bioresource Technology, 122, pp. 27-34, 2012.

[15] Xu, P., Drewes, J.E., Kin, T., Bellon, C. \& Amy, G., Effect of membrane fouling on transport of organic contaminants in NF/RO membrane applications. Journal of Membrane Science, 279, pp. 165-175, 2006.

[16] Sabbatini, P., Rossi, F., Thern, G., Marajofsky, A. \& Fidalgo de Cortalezzi, M.M., Iron oxide adsorbers for arsenic removal: A low cost treatment for rural areas and mobile applications. Desalination, 251, pp.184-192, 2010.

[17] Devi, R.R., Umlong, I.M., Das, B., Borah, K., Thakur, A.J., Raul, P.K., Banerjee, S. \& Singh, L., Removal of iron and arsenic (III) from drinking water using iron oxide-coated sand and limestone. Applied Water Science, 4, pp.175-182, 2014.

[18] Logsdon, G., Hess, A. \& Horsley, M., Guide to selection of water treatment processes (Chapter 3). Water quality and treatment, ed. R.D. Letterman, McGraw-Hill: New York, pp. 36-37. 